\title{
Biomechanical analysis of wave-induced mortality in the marine alga Pterygophora californica
}

\author{
Richard F. Biedka, John M. Gosline \& Robert E. De Wreede \\ Departments of Zoology and Botany, University of British Columbia, Vancouver, British Columbia V6T 2B1, Canada
}

\begin{abstract}
A biomechanical analysis was carried out on the stipe of the marine brown alga Pterygophora californica (Ruprecht). Tensile and compressive mechanical tests on the cortical material revealed that the plant is constructed from a reasonably stiff (tensile modulus of elasticity $=60$ $\mathrm{MN} \mathrm{m}^{-2}$ ), strong (tensile strength $=9 \mathrm{MN} \mathrm{m}^{-2}$ ) and extensible (failure strain $=0.49$ ) material. Consequently, the stipe is a very robust structure that is extremely difficult to break. However, the work of fracture of the cortical material is only about $400 \mathrm{~J} \mathrm{~m}^{-2}$, making it a relatively brittle material. Thus, it is expected that small notches or flaws at the stipe surface will dramatically reduce the ability of the stipe to resist bending forces caused by waves. Fracture mechanics analysis suggests a critical flaw size for the cortical material of about $0.2 \mathrm{~mm}$, and any surface defect larger than this size will degrade the mechanical strength of the plant. The red urchin Strongylocentrotus franciscanus is known to graze on the stipe of $P$. californica. This grazing is known to introduce surface flaws an order of magnitude or more larger than the critical flaw size, and therefore it is very likely that such grazing will make a substantial contribution to wave-induced mortality of these plants.
\end{abstract}

\section{INTRODUCTION}

The survival of animals and plants in the waveswept intertidal is determined largely by their ability to resist or avoid the large forces caused by breaking waves. Small organisms commonly escape these forces by living in micro-habitats where flow forces are small (Denny et al. 1985), but intertidal macro-algae, by virtue of their size, are unable to use this strategy. Many algae, however, avoid large forces because they are very flexible and can move with strong currents or breaking waves. This reduces the velocity of the water relative to the plant and dramatically reduces the force that the plant experiences (Koehl \& Wainwright 1977. Koehl 1984). The brown alga Pterygophora californica (Ruprecht) appears to be an exception to this generalization.

Pterygophora californica is a perennial brown seaweed which inhabits the rocky subtidal of the west coast of temperate North America. The plant is 'treelike' in that the stipe is rigid enough to support the blades, even when the alga is fully exposed at extreme low tides. Wave surge will generate large drag forces, primarily on the blades (Charters et al. 1969), and these drag forces will be translated into bending moments that create large bending stresses at the base of the stipe. Thus, it is likely that this plant will fail by bending fracture at the base of its stipe. In addition, any local damage to the basal region would cause a stress concentration that would make fracture even more likely (Gordon 1978).

Individual specimens of Pterygophora californica have been found detached and cast ashore by the tide (MacMillan 1902). Excessive wave motion coupled with grazing by sea urchins are 2 events that have been suggested to account for such mortality (De Wreede $1984,1986)$. This study provides an analysis of the fracture properties of $P$. californica. The mechanical properties of the major support tissue in the stipe, the cortex, were measured, and these properties were used to assess the possible role of damage caused by sea urchin grazing to plant mortality. The analysis indicates that although the cortex material is reasonably strong and extensible, it is quite brittle and thus easy to break. As is the case with all brittle materials, small flaws are important in initiating fracture processes. Thus, it is very likely that damage to the stipe from herbivores could contribute to the mortality of this plant. 


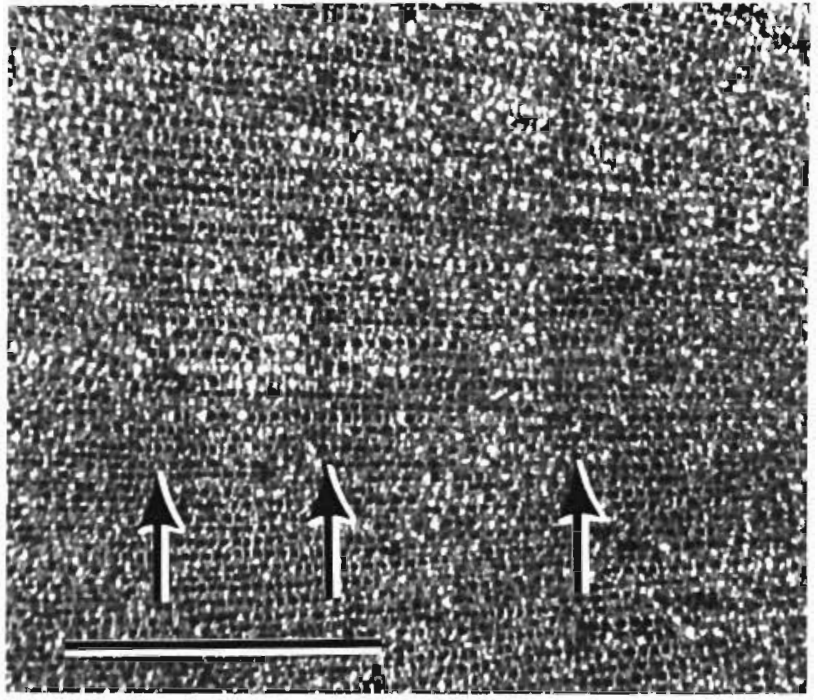

Fig. 1. Pterygophora californicā. Light micrograph of crosssection through the stipe. The cells radiate in rows from the right (medulla) to the left (meristoderm). The 3 growth rings visible in this section are indiciated with arrows. Scale bar $=$ $2 \mathrm{~mm}$

\section{MATERLALS AND METHODS}

Individual Pterygophora californica were collected from Sooke Harbor and Barkley Sound, Vancouver Island, British Columbia, Canada. The algae were maintained in aerated $28 \mathrm{ppt}$ seawater for up to $3 \mathrm{wk}$ prior to testing. The stipe of $P$. californica consists of several cell types (MacMillan 1902). Two predominant types are shown in Fig. 1; the radially oriented rows of cells and the concentric growth rings. The growth rings are deposited annually and aid in determining the age of this species (De Wreede 1984). Since the cortex supports the majority of the bending stresses and comprises $90 \%$ of the stipe, the cortical region was selected for the construction of test specimens.

Preparation of test specimens for tensile tests began by cutting a $5 \mathrm{~cm}$ portion from the basal region of the stipe, a region that is continually stressed in bending and often grazed by sea urchins (De Wreede 1984). The $5 \mathrm{~cm}$ long portions of stipe were planed into rectangular blocks about 1.5 to $2 \mathrm{~cm}$ wide from which 2 to $3 \mathrm{~mm}$ thick strips of cortex were cut with a single edged razor blade. Four different orientations of the strips were tested (Fig. 2). Specimen L1: cut from plant with longer radial rows of cells and discontinuous growth rings, tested longitudinally. Specimen $45^{\circ}$ : same sample as L1, but tested at $45^{\circ}$ to the long axis of stipe. Specimen $90^{\circ}$ : same sample as L1, but tested at $90^{\circ}$ to the long axis of the stipe. Specimen L2: cut from plant with growth rings continuous, but with shorter radial rows of cells (see Fig. 2A); tested longitudinally. Specimens

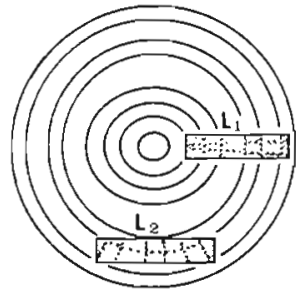

A

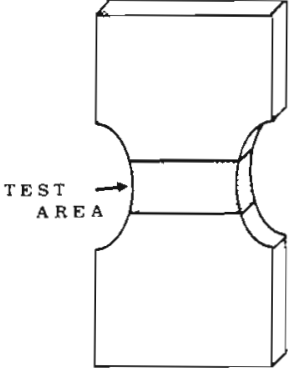

B
Fig. 2. Pterygophora californica. (A) Cross-section of stipe showing origin of L1 and L2 test specimens. The L1 and L2 specimens were tested parallel to the long axis of the stipe. The $45^{\circ}$ and $90^{\circ}$ test specimens are variations of the L1 specimen, but were tested at $45^{\circ}$ and $90^{\circ}$ relative to the long axis of the stipe, respectively. (B) Typical tensile test specimen, showing fiducial marks that denote test area

were cut into the desired dumb-bell shape, as shown in Fig. 2B.

The dumb-bell shape test specimen was selected to provide a test area of reduced cross-section in which failure always occurred. The broad area at each end was held firmly by the test apparatus. Specimens were held with pneumatic grips at reduced pressure (15 psi), and were tested in an Instron Model 1122 Tensile Testing machine. In all tests the specimen was stretched at a rate of $5 \mathrm{~mm} \mathrm{~min}^{-1}$, giving an approximate strain rate of $0.2 \mathrm{~min}^{-1}$.

Although the Instron measures force and cross-head movement, it is not possible to determine the strain in the test region of the dumb-bell shaped specimens strictly from this information. For this reason, the strain values for tensile tests were calculated from the length changes recorded by a Video Dimension Analyser (VDA) (Instruments for Physiology and Medicine Model 303, LaJolla, California). The L1 and L2 test orientations were labelled with 2 parallel black and white reference lines, running perpendicular to the long axis of the test area. The $45^{\circ}$ and $90^{\circ}$ test specimens were marked using 2 thin copper wires $(130 \mu \mathrm{m}$ diameter) which protruded at right angles to the test area. These reference marks were followed by the VDA. The cross-sectional dimensions of the test area were measured with calipers prior to mounting in the Instron. Tensile tests were also conducted on whole juvenile stipes. Each end of the stipe was clamped in the Instron and tested as previously described. Throughout the experimentation and specimen preparation, test specimens were continually bathed in seawater to prevent dehydration.

Compression tests were run on small blocks of tissue of uniform cross-section which were cut from the same region as the tensile test specimens. The uniform crosssection allows the strain to be calculated directly from 
the Instron cross-head movement. The force and extension data were converted into stress, strain, modulus of elasticity and energy to failure for both tensile and compressive data as described below.

The stress $(\sigma)$ is the force $(F)$ per cross-sectional area (A) and is measured in newtons per square meter $\left(\mathrm{N} \mathrm{m}^{-2}\right)$. The strain $(\varepsilon)$ is the change in length $(\Delta \mathrm{L})$ of the test specimen divided by the original length $\left(\mathrm{L}_{0}\right)$, and indicates the degree of extension of the material. The modulus of elasticity ( $E$ ) gives the stiffness of the material, and is determined by the slope of the linear portion of the stress-strain curve. The energy to failure (W) is the total area beneath the stress-strain curve. This area is equal to the energy per unit volume required to break the material, expressed as $\mathrm{J} \mathrm{m}^{-3}$, and provides an indication of the toughness of the material. Stress-strain curves were photocopied, cut out and weighed. This weight was compared to the weight of a known area of paper to determine the area of the curve.

Test specimens of cortex for tear experiments were sliced to a thickness of $0.3 \mathrm{~mm}$ with a sledge microtome from $5 \mathrm{~cm}$ long portions of whole stipe. Tears were initiated either longitudinally or transversely by a $5 \mathrm{~mm}$ cut in the appropriate direction, as shown in Fig. 3 . The 2 segments on either side of the initiation

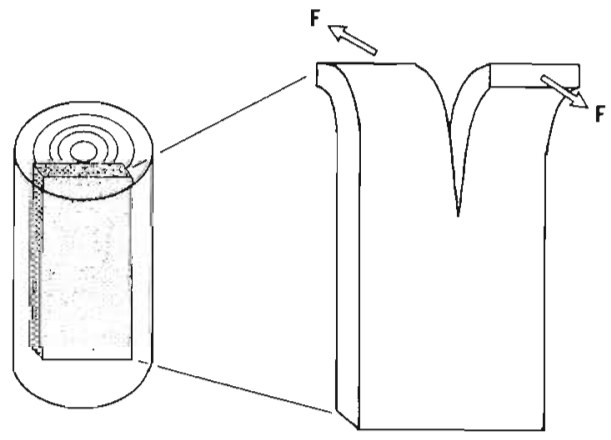

Fig. 3. Pterygophora californica. Longitudinal tear test specimen. Sheet of cortical material is planed from the stipe, prepared as shown and torn in the direction indicated by the arrows. The preparation of a transverse tear specimen is identical, but torn perpendicular to longitudinal example

cut were clamped in the Instron so that the cut would enlarge into a self-propagating crack when the clamped ends were pulled apart. The work of fracture $(\gamma)$ is the energy required to create new surface areas in a tear. It is calculated as the force $(F)$ times the tear distance divided by twice the sample thickness area, yielding the work of fracture in $\mathrm{J} \mathrm{m}^{-2}$.

Scanning electron microscopy (SEM) was used to observe fracture surfaces and analogous regions of unstressed material. Material for SEM was fixed in $4 \%$ formalin in seawater for $24 \mathrm{~h}$, washed in distilled water for $15 \mathrm{~min}$, and freeze dried. The dried material was mounted on aluminum studs with high purity silver paint, allowed $30 \mathrm{~min}$ to set, and coated with a paladium/gold mixture in a sputter coater.

Material for polarized light microscopy was cut from the stipe and mounted on a freeze plate microtome Sections $30 \mu \mathrm{m}$ thick were cut at various angles $(0$ to $90^{\circ}$ through stipe) and mounted permanently with Turtox CMC-10 mounting medium. Observations were made under both bright field and polarized light with a Wild M21 polarizing microscope.

Statistical tests were evaluated at the 0.05 level of significance. Comparisons of tensile tests, L2, L1, 45․ and $90^{\circ}$, were done using a 1 -way analysis of variance (ANOVA; Sokal \& Rohlf 1969). The data were tested for homogeneity of variance (Sokal \& Rohlf 1969), and transformed when necessary using a logarithmic transformation. Multiple comparisons, using a Student Newman-Keuls test (Zar 1974), were used to identify statistical differences among the tensile test group means. Additional statistical comparisons of tensile and compressive data as well as work of fracture data were done using a 2-tailed Students t-test ( $Z$ ar 1974).

\section{RESULTS}

Initial mechanical tests were conducted to quantify the fracture stress and strain in the mature stipe. The fresh stipe is very flexible and very slippery. Initial manipulation of the stipe proved to be uneventful, even when large bending moments were applied by hand. The toughness and slipperiness of the mature stipe made it virtually impossible to break it by hand, or with the aid of a long lever used to increase mechanical advantage. The stipe would bend more than $360^{\circ}$ without breaking, making it difficult to quantify its fracture properties. Fracture could only be initiated when the stipe was notched; it then snapped cleanly in two with little effort. This implied that the stipe was composed of a very brittle material and was notchsensitive despite the flexibility observed when it was manipulated by hand. This suggests that Pterygophora californica is vulnerable to herbivore grazing or abrasion which could create notches in the stipe. Because it is virtually impossible to evaluate the fracture of the intact plant in bending, an analysis of the mechanical properties of the cortical material was undertaken. Bending involves a combination of tensile and compressive forces, as in a beam, and thus the analysis of tensile and compressive material properties should provide a basis for predicting the fracture behaviour of the whole plant.

A typical tensile test record for one of the dumb-bell shaped specimens is shown in Fig. 4. Region ' $A$ ' in Fig. 4 is the realignment of the specimen as it is pulled 


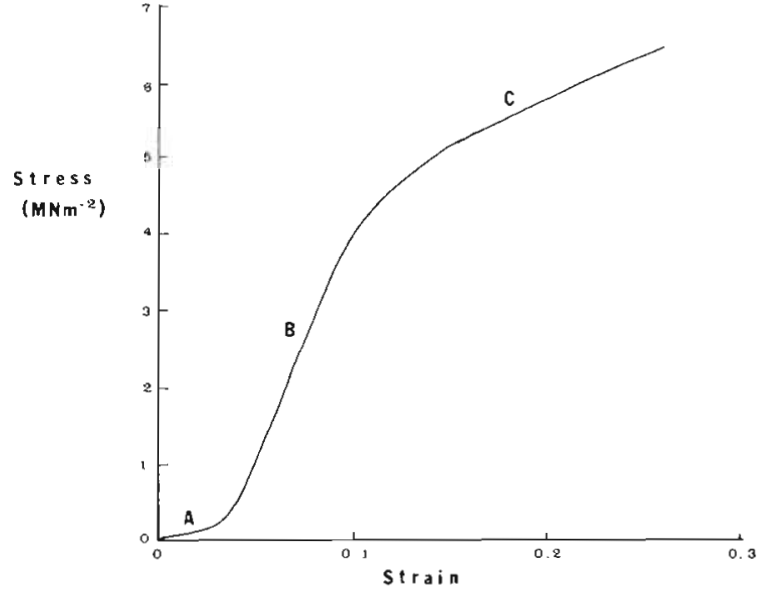

Fig. 4. Pterygophora californica. Typical tensile test record for cortical material. See text for explanation of regions A, B, and $\mathrm{C}$

taut. Further continuous pulling increases the force quickly and stretches the test specimen (region ' $B$ ' in Fig. 4). Region ' $\mathrm{B}$ ' is the linear portion of the stressstrain curve and the slope of this region gives the tensile modulus of elasticity. If the force is removed at any point along this portion of the curve, the specimen will return to its original size and shape. Region ' $C$ ' in Fig. 4 is beyond the linear elastic portion of the stressstrain curve where the material yields and plastic deformation occurs. This region of the curve is characterised by its reduced slope. In Fig. 4 yield occurred at a stress of $3.75 \mathrm{MN} \mathrm{m}^{-2}$ and a strain of $0.095(9.5 \%$ extension). Beyond the yield point the material deformed irreversibly until it fractured at a strain of 0.28 . Mean values for the stress and strain at failure, the modulus of elasticity and the energy to fracture from the tensile tests are shown in Table 1. Limited data were also collected from the whole stipe tested in tension; mean values of these tests are also shown in Table 1.

Statistical analysis of the failure stress data for the 4 different orientations, using an ANOVA, indicated significant differences at the 0.05 level. Failure stresses ranged from $4.0 \mathrm{MN} \mathrm{m}^{-2}$ in an L1 specimen to 16 $\mathrm{MN} \mathrm{m}^{-2}$ in an L2 specimen. Despite overlap within the data, a Student Newman-Keuls (SNK) multiple comparison test showed that all groups were significantly different, except the comparison of the $90^{\circ}$ and $45^{\circ}$ specimens. Statistical analysis of the 4 tensile test groups for strain at failure using an ANOVA again showed significant differences. The data set for the strain however is quite homogeneous and overlaps more than the stress data. The strains range from a low of $17 \%$ in a $90^{\circ}$ specimen to a high of $70 \%$ in a L2 specimen. Application of the SNK test, however, failed to show any significant differences between the groups. The modulus of elasticity data overlap in many cases and appear homogeneous, but an ANOVA indicated significant differences at the 0.05 level. The SNK test supported the ANOVA in all comparisons, except the $\mathrm{L} 2$ and $45^{\circ}$. The energy to failure (W) is the only parameter where obvious differences exist. The $90^{\circ}$ data are consistently higher. The L1 and $45^{\circ}$ overlap to a greater extent and lie between the 2 other groups. An ANOVA indicated significant differences, and the SNK test supported the ANOVA, indicating a statistical difference between each of the groups.

In addition to tensile forces, bending involves compressive forces. A typical stress-strain curve recorded

Table 1. Pterygophora californica. Summary of tensile and compressive mechanical tests on outer cortical material. For tensile tests $\varepsilon$ gives the strain and $\sigma$ the stress at specimen failure, $E_{t}$ gives the tensile modulus of elasticity, and $W$ gives the energy required to break the specimen. Four different test specimens were used in tensile tests, as described in 'Materials and Methods'. For compression tests $\varepsilon_{\mathrm{y}}$ and $\sigma_{\mathrm{y}}$ give the strain and stress at yield, respectively, and $\varepsilon_{\mathrm{c}}$ gives the compressive modulus of elasticity; $\overline{\mathrm{X}}$ : mean; N: number of replicates; SE: standard error

\begin{tabular}{|c|c|c|c|c|c|c|c|c|c|c|}
\hline \multicolumn{11}{|c|}{ Tensile test results } \\
\hline & \multicolumn{2}{|c|}{ L1 } & \multicolumn{2}{|c|}{$45^{\circ}$} & \multicolumn{2}{|c|}{$90^{\circ}$} & \multicolumn{2}{|c|}{ L2 } & \multicolumn{2}{|c|}{ ANOVA } \\
\hline & $\overline{\mathrm{X}}$ & $N$ & $\bar{X}$ & $N$ & $\bar{X}$ & $\mathrm{~N}$ & $\overline{\mathrm{X}}$ & $N$ & $\mathrm{df}$ & F-value \\
\hline$\varepsilon$ & 0.34 & 10 & 0.32 & 7 & 0.22 & 9 & 0.49 & 10 & 3,32 & 12.3 \\
\hline$\sigma\left(\mathrm{MN} \mathrm{m}^{-2}\right)$ & 5.7 & 10 & 8.0 & 7 & 8.1 & 9 & 9.2 & 10 & 3,32 & 9.8 \\
\hline $\mathrm{E}_{\mathrm{t}}\left(\mathrm{MN} \mathrm{m}^{-2}\right)$ & 45.2 & 10 & 56.9 & 7 & 86.3 & 9 & 60.5 & 10 & 3,32 & 4.1 \\
\hline $\mathrm{W}\left(\mathrm{MJ} \mathrm{m}^{-3}\right)$ & 0.98 & 8 & 1.31 & 7 & 0.59 & 9 & 2.6 & 10 & 3,30 & 10.4 \\
\hline \multicolumn{11}{|c|}{ Compressive test results } \\
\hline & $\overline{\mathrm{X}}$ & $N$ & $\mathrm{SE}$ & & & & & & & \\
\hline$\varepsilon_{\mathrm{y}}$ & 0.32 & 11 & 0.03 & & & & & & & \\
\hline$\sigma_{y}\left(\mathrm{MN} \mathrm{m}^{-2}\right)$ & 4.45 & 11 & 0.63 & & & & & & & \\
\hline $\mathrm{E}_{\mathrm{c}}\left(\mathrm{MN} \mathrm{m}^{-2}\right)$ & 14.40 & 11 & 0.09 & & & & & & & \\
\hline
\end{tabular}




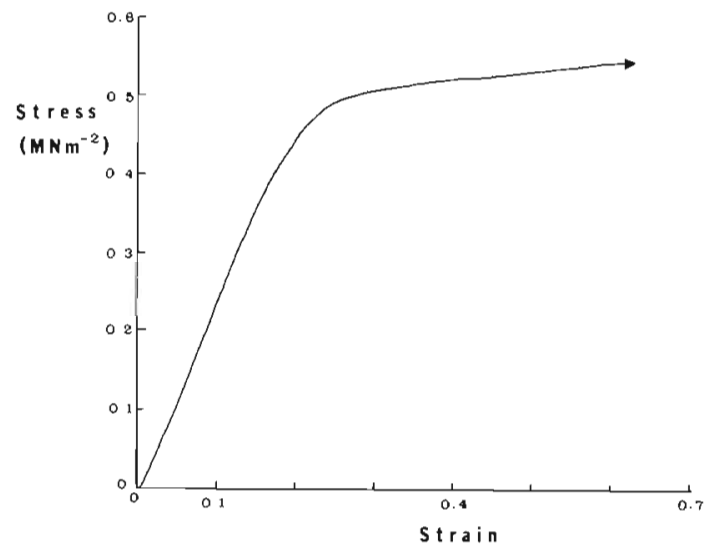

Fig. 5. Pterygophora californica. Typical compressive test record for cortical material

in compression is shown in Fig. 5. The initial low stiffness region seen in tensile tests is not seen in compressive tests because the block-shaped specimen does not reorientate as the force is applied to it. The initial portion of the stress-strain curve shows linear elastic deformation, with a mean compressive modulus of elasticity of $14.4 \mathrm{MN} \mathrm{m}^{-2}$. Thus, the compressive stiffness of the material is about one quarter of its stiffness in tension. This difference between tensile and compressive modulus of elasticity is statistically significant. Beyond approximately $30 \%$ extension, the material yields and starts to deform plastically. This type of deformation can continue to extremely high strains without obvious rupture, but no attempt was made to quantify this fracture property. The data for yield stress, yield strain and initial modulus of elasticity are recorded in Table 1.

The work of fracture $(\gamma)$ represents the fracture toughness of the material. A typical set of data for the 'trouser tear' test of a thin section $(0.3 \mathrm{~mm})$ of cortex is shown in Fig. 6. Region 'A' of Fig. 6 is the initial rising portion of the curve representing the loading of the material to a stress at which a stable elongation of the crack will occur. Once the crack has begun to grow, no

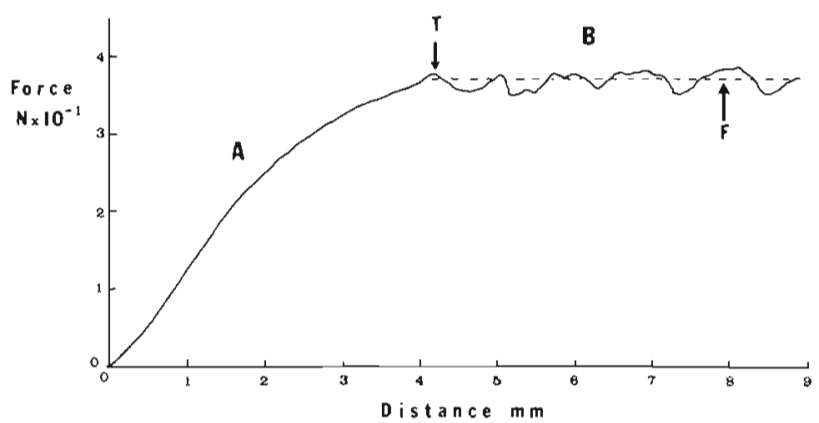

Fig. 6. Pterygophora californica. Typical tear test record. T: point at which the tear begins; $F$ : average force used to calculate the work of fracture additional force is required. Region ' $\mathrm{B}$ ' in Fig. 6 is the flat portion of the curve corresponding to stable crack growth. The calculated work of fracture for longitudinal tearing is greater than that for transverse tearing. The mean longitudinal work of fracture is $823 \mathrm{~J} \mathrm{~m}^{-2}$ ( $\mathrm{SE}=112, \mathrm{n}=12)$, whereas the mean transverse work of fracture is $415 \mathrm{~J} \mathrm{~m}^{-2}(\mathrm{SE}=33.5, \mathrm{n}=10)$. These values are significantly different at the 0.05 level.

Scanning electron micrographs (SEM) were taken of transverse and longitudinal tear surfaces, of fracture surfaces and of smooth tissue surfaces cut with a clean razor blade. In general, the tear and fracture surfaces are barely different from the cut surfaces (Fig. 7). The box-like cells are only slightly distorted, and there is little evidence of fibre pull-out in the plane of fracture.

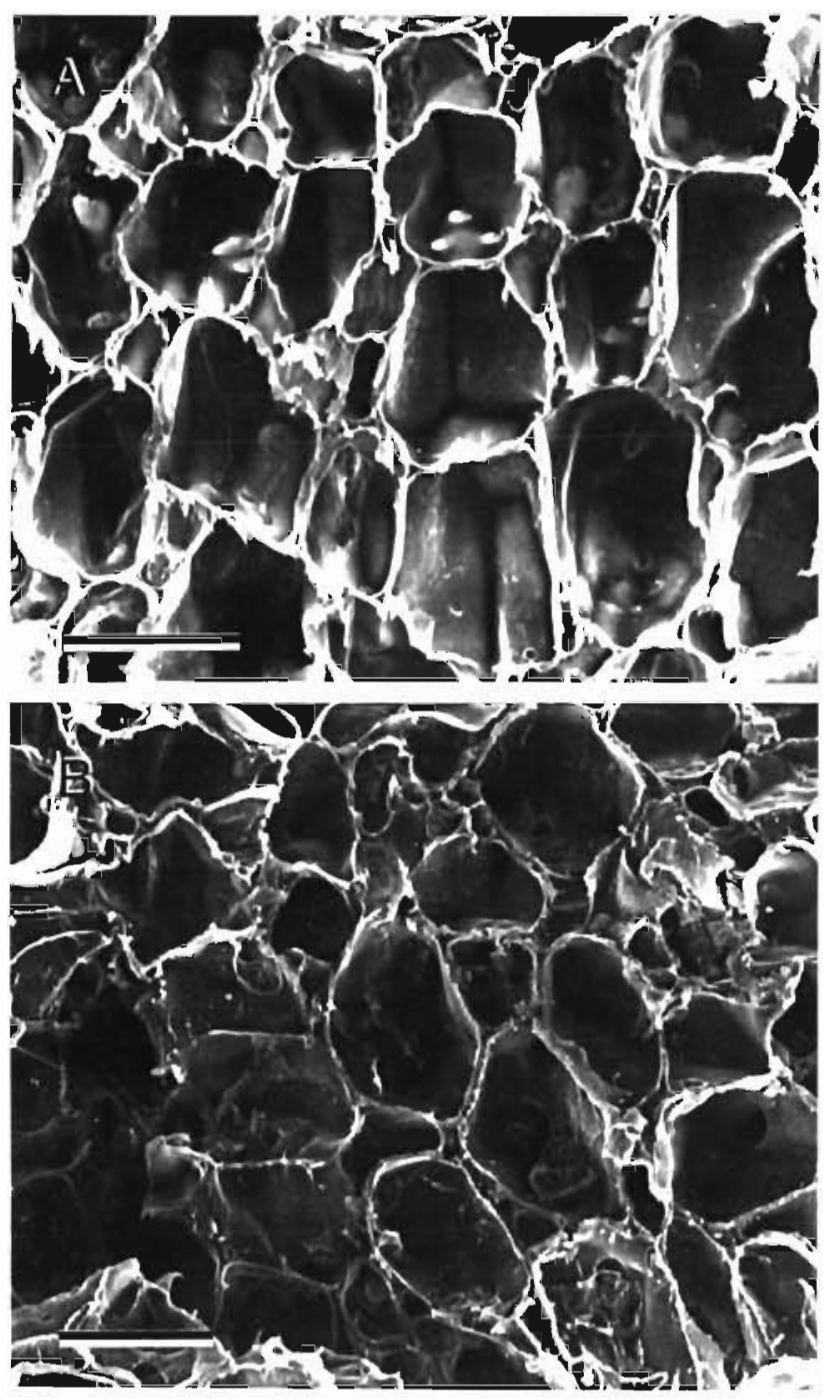

Fig. 7. Pterygophora californica. Scanning electron micrographs of cortical material. (A) Cut surface showing undistorted polygonal shape of cell walls. (B) Transverse tear surface showing some distortion of cell shape but with actual fracture surface being nearly as smooth as the cut surface. Scale bars $=40 \mu \mathrm{m}$ 
Such smooth fracture and tear surfaces are commonly seen for brittle materials, and are consistent with the low work of fracture $(\gamma)$ values reported above.

Although the tear and fracture surfaces were quite smooth, there appeared to be significant differences between the surfaces created in longitudinal and transverse tears. The transverse tear surface is very uniform (Fig. $7 B$ ), whereas the longitudinal tear surface is quite rough, with individual cells torn in many directions. Longitudinal tears cross the radially orientated rows of cells and shatter individual cells as they progress. Transverse tears, on the other hand, probably progress between the columns of radially oriented cells. This difference likely explains the lower work of fracture values recorded for the transverse direction.

\section{DISCUSSION}

\section{Mechanical organization of the stipe material}

The extreme robustness of the intact stipe made it impossible to evaluate the fracture behaviour of the whole plant. For this reason, tensile and compressive tests on samples of cortical material are used to provide a basis for an analysis of the whole structure. Unfortunately, the tensile test specimens exhibited different properties amongst themselves as a group, and it is necessary to consider these results in some detail. The cellular arrangement within each of the tensile specimens (L1, L2, etc.) is a function of specimen preparation, where either growth rings or radially orientated rows of cells were selected. In addition to this, cellulose fibre orientation can influence the mechanical properties of the cell wall material. Therefore, before discussing the mechanical properties of the intact stipe, one must look closely at (1) the arrangement of the cells within the stipe, and (2) the orientation of the cellulose fibers within individual cell walls. These are probably the 2 key factors which determine the mechanical anisotropy of the major structural material in the stipe.

The individual cells in the cortex are quite regular and 'box-like' in shape, but they are arranged in spatial patterns which suggest higher levels of structural organization. First, the cells are arranged in radial rows, running from the centre of the stipe to the periphery. Second, these radial rows are periodically interrupted by concentric growth rings of denser cells (Fig. 1). This gives rise to the distinct banding pattern of the growth rings. Two of the tensile test orientations were used to assess the relative importance of radial rows and growth rings to the mechanical properties of the outer cortical material. The L1 specimens were cut to leave the radial rows intact, and the L2 test speci- mens were cut to leave the concentric growth rings largely intact. The contribution of the cellulose fiber orientation to this comparison can probably be ignored because both types of specimen were tested in the same direction. The L2 specimens show significantly higher modulus of elasticity, strength, extensibility and work of fracture relative to the L1 specimens, all suggesting that the concentric growth rings act as a major structural component of the stipe. For this reason we use the results of the L2 test to provide an indication of the mechanical behaviour of the intact stipe. Comparison of the stiffness of L2 specimens $(60$ $\mathrm{MN} \mathrm{m}^{-2}$ ) with comparable data from whole juvenile stipes (stiffness $72 \mathrm{MN} \mathrm{m}^{-2}$ ) suggests that this assumption is reasonable, if not exact.

Comparison of the L1 and $90^{\circ}$ test specimens provides some information on the role of cellulose fibre orientation to the structural organization of the stipe. The cellulose fibres in each cell wall are packed into dense mats to form a material which is best described as a fibre-reinforced composite (for review see Stewart 1974). The angle at which the fibers are oriented in this mat will determine the mechanical properties in different directions (Wainwright et al. 1976). Both the axial (L1) and radial $\left(90^{\circ}\right)$ tests were carried out on samples cut with the radial rows intact. Thus, any differences should arise primarily from the cellulose fibre angle. The $90^{\circ}$ specimens have a significantly higher modulus of elasticity, and this suggests a fibre angle somewhat greater than $45^{\circ}$ relative to the long axis of the stipe. The axial:radial stiffness ratio is $0.52: 1$, and from fibre-reinforced composite theory this would correspond to a cellulose fibre angle of about $50^{\circ}$ (Wainwright et al. 1976). Similarly, it is likely that a cellulose fibre angle greater than $45^{\circ}$ accounts for the somewhat greater extensibility in the axial direction (Table 1), because a greater degree of fibre reorientation can occur before the specimen ruptures. The greater stiffness of the $90^{\circ}$ specimen probably accounts for the decreased fracture toughness exhibited in this orientation.

Polarized-light microscopy of thin sections cut at various angles relative to the long axis of the plant support these conclusions. All sections were found to exhibit roughly equal birefringence. Although the birefringence data were not analyzed in detail, they are consistent with an average cellulose angle near $45^{\circ}$ and also indicate that there is considerable variation around the mean fibre angle.

\section{Mechanics of stipe bending}

In the ocean the algae are not stressed totally in tension, but primarily in bending. Loading the stipe in 
bending develops 3 distinct loading regimes: (1) tension on the convex surface of the stipe, (2) compression on the concave surface, and (3) a non-loaded central area (the neutral axis) that separates the tensile and compressive regions of the stipe (Wainwright et al. 1976). Thus, axial compression plays an important role in the mechanics of the stipe.

Our data indicate that the mechanical properties of the cortical material are significantly different in compression than in tension. Specifically, the mean compression modulus of elasticity is only one quarter of the tensile modulus of elasticity. These differences can be explained in terms of the cellular architecture of the material. In tensile tests the cell walls are pulled taut and then stretched. Thus, tensile tests actually determine the tensile properties of the cell wall material. In compression tests, however, the mode of deformation is quite complex because the cell walls are thin and will buckle and fold in on themselves under compressive loads. This large difference in tensile and compressive stiffness plays an important role in the alga's design to resist bending forces from breaking waves.

Although Pterygophora californica appears to be a rigid, 'tree-like' plant, it is rigid only when compared to other brown algae. In fact, it is very flexible when compared to a real tree. These differences arise in part from differences in the tensile stiffness of the structural materials in the plants. That is, the tensile stiffness of the cortical material of $P$. californica is about 6 times greater than that of the bull kelp Nereocystis luetkeana (Mert.) Post. \& Ruprecht (Koehl \& Wainwright 1977), but it is only about one hundredth the stiffness of wood (Wainwright et al. 1976). Thus P. californica, like all other brown algae, deals with environmental forces by being flexible (Koehl 1984). This flexibility is due in part to the fact that the plant is constructed from a material with relatively low tensile stiffness and considerable extensibility, but in addition the large difference in tensile and compressive stiffness of the cortical material plays an important role.

A cylindrical beam made from a material with equal tensile and compressive properties will have its neutral axis located at the centre of the beam. The stress caused by bending, which increases linearly with distance from the neutral axis (Wainwright et al. 1976), will be equal on the tensile and compressive sides. If, however, the modulus of elasticity of the material in compression is lower than that in tension, the neutral axis will be shifted towards the tension side of the beam, and tensile stresses will be reduced at any given degree of bending. This means that the stipe can be bent much further before the material on the tensile surface reaches its breaking stress and the stipe fractures. Although a detailed analysis of this process is beyond the scope of this study, it is clear that Ptery- gophora californica achieves a substantial degree of flexibility in bending using this mechanism, without compromising axial stiffness. This probably explains why it is virtually impossible to break an intact stipe in bending, and why $P$. californica can survive the impact of large storm waves.

\section{Fracture of the stipe}

Although the extreme flexibility described above makes it unlikely that the intact stipe will fracture in bending, the presence of small flaws or notches on the tensile surface will create stress concentrations that can initiate fracture processes (Wainwright et al. 1976). This property is well documented in the energy to break (W) and work of fracture $(\gamma)$ data presented here. The energy required to break an unflawed L2 tensile test specimens is $2.6 \mathrm{MJ} \mathrm{m}^{-3}$. This value is high indeed, and reflects the large amount of energy required to break the intact plant. For comparision, collagen, the fibrous protein that makes up tendons and ligaments in the vertebrate body, has an energy to break of about $5 \mathrm{MJ} \mathrm{m}^{-3}$, or about twice that for the cortical material of Pterygophora californica. However, in the presence of a pre-existing flaw, the energy required to propagate a growing crack, as expressed by the work of fracture, is very low for the cortical material. The work of fracture for transverse tears, the relevant direction for fracture in bending, is only about $400 \mathrm{~J} \mathrm{~m}^{-2}$, a value only about an order of magnitude greater than that for an extremely brittle material such as glass. High toughness, composite materials such as horse hoof keratin or fibreglass have works of fracture of the order of $10^{5} \mathrm{~J} \mathrm{~m}^{-2}$ (Gordon 1978). The low work of fracture for $P$. californica cortex indicates that once a crack in the stipe begins to grow it will propagate rapidly and the plant will fail catastrophically. The question then becomes, what conditions are required to initiate crack growth?

The engineering theory of fracture mechanics can be used to describe the initiation of crack growth. At its simplest, the theory provides a relation that can be used to estimate the size of flaw, a, that will initiate brittle fracture under a given stress level for any kind of material:

$$
\mathrm{a}=\frac{2 \mathrm{E} \gamma}{\pi \sigma^{2}}
$$

where $\mathrm{E}=$ tensile modulus of elasticity; $\gamma=$ work of fracture; $\sigma=$ stress. Eqn (1) can now be used to estimate the conditions necessary to initiate a transverse crack across a Pterygophora californica stipe in bending. When values for $E$ and o from the L2 test specimens, and the $\gamma$ value for transverse tears are put into this equation, the calculated critical flaw length 
becomes $0.2 \mathrm{~mm}$ (larger than the inserted copper wire reference marker). Although this is only an approximation, this critical crack length is very small and is characteristic of a brittle material. It means that a stipe which contains any flaw larger than about $0.2 \mathrm{~mm}$ long will undergo a catastrophic brittle fracture at a stress less than the tensile strength of the cortical material.

Strong waves are not the only concern to the alga's survival. Herbivory is also a problem. The red urchin Strongylocentrotus franciscanus (Agassiz) is an effective grazer of the stipe, and it seems likely that grazing by sea urchins might introduce notches in the stipe that are an order of magnitude or more larger than the critical flaw size calculated for the unnotched stipe. Thus grazing may dramatically lower the stress levels needed to initiate brittle fracture of the stipe, and may contribute to wave-induced mortality in this alga. What remains to be demonstrated is that the flow forces experienced in the ocean actually create the stress levels that this fracture analysis suggest are needed to break the stipe. It is not uncommon for Pterygophora californica to experience water velocities of $2 \mathrm{~m} \mathrm{~s}^{-1}$, and velocities as high as $14 \mathrm{~m} \mathrm{~s}^{-1}$ may occur during storms (Charters et al. 1969). These flow velocities will undoubtedly impose very large drag forces on the plant (Denny et al. 1985), and it seems quite likely that 'flawed' plants may well fail under these conditions.

We have not tested the effect of the $50 \mu \mathrm{m}$ thick layer of meristoderm cells on the mechanical integrity of the stipe. However, since the meristaderm is a newly formed layer of small cells, is less than the critical crack length, and is usually removed by sea urchin grazing, we believe this layer to be mechanically unimportant to the overall properties of the stipe.

In summary, Pterygophora californica, like other marine algae, survives the forces caused by wave action by being flexible. Although $P$. californica is not as flexible as some of the common inter-tidal algae, it can be deformed extensively without breaking, even though it is constructed from a very brittle material This flexibility arises in part from the difference in the tensile and compression moduli of the cortical material. Although the plant's flexibility makes it difficult to break, the brittle nature of the outer cortex material renders the plant susceptible to catastrophic fractures initiated at small flaws. Thus herbivore grazing of the stipe may subject the plant to substantial wave-induced mortality.

Acknowledgements. This research was supported by NSERC grant A6934 to J.M. G., and NSERC grant 67-9872 to R. E. DW.

\section{LITERATURE CITED}

Charters, A. C., Neushul, M., Barilotti, D. C. (1969). The functional morphology of Eisenia arborea. Proc. Int. Seaweed Symp. 6: 89-105

Denny, M. W., Daniel, T. L., Koehl, M. A. R. (1985). Mechanical limits to size in wave swept organisms. Ecol. Monogr. 55: 69-102

De Wreede, R. E. (1984). Growth and age class distribution of Pterygophora californica (Phaeophyta). Mar. Ecol. Prog. Ser. 19: 93-100

De Wreede, R. E. (1986). Demographic characteristics of Pterygophora californica (Laminariales, Phaeophyta). Phycologia 25: 11-17

Gordon, J. E. (1978). Structures, or why things don't fall down. Penguin Books Canada Ltd

Koehl, M. A. R. (1984). How do benthic organisms withstand moving water? Am. Zool. 24: 57-70

Koehl, M. A. R., Wainwright, S. A. (1977). Mechanical design of a giant kelp. Limnol. Oceanogr. 22: 1067-1071

MacMillan, C. (1902). Observations on Pterygophora californica. Minnesota Botanical Studies 2: 723-741

Stewart, W. D. P. (1974). Algal physiology and biochemistry. Bot. Monogr. Univ. of Calif. Press 10: 40-85

Sokal, R., Rohlf, F. J. (1969). Biometry. W. H. Freeman and Co., San Francisco

Wainwright, S. A., Biggs, W. D., Currey, J. D., Gosline, J. M. (1976). Mechanical design in organisms. John Wiley, New York

Zar, J. H. (1974). Biostatistical analysis. Prentice-Hall, New Jersey 